\title{
COMERCIO E INMIGRACIÓN EN LA PROVINCIA COSTEÑA. LOS ITALIANOS DE EL CARMEN DE BOLÍVAR: EL CASO DE LOS VOLPE
}

Wilson Blanco Romero*

\section{INTRODUCCIÓN}

El objeto de este trabajo ${ }^{1}$ es mostrar un aspecto de la historia de la provincia costeña del cual poco se han ocupado los investigadores del pasado, como es el de la presencia de la inmigración extranjera y su influencia en la vida económica y empresarial en ese ámbito.

El espacio del cual nos ocupamos corresponde a la subregión de los Montes de María o Serranía de San Jacinto, en la que está enclavada la población de El Carmen de Bolívar. Ésta, como sabemos, ha jugado un papel central en el desarrollo de la economía tabacalera de exportación, que en la segunda mitad del siglo XIX, mucho antes que el café, vinculó la producción agrícola colombiana al moderno mercado mundial ${ }^{2}$, al tiempo que contribuyó decisivamente a la modernización de los medios de transporte, sumi-

* Facultad de Ciencias Humanas, Programa de Historia, Universidad de Cartagena.

1. Este artículo es resultado de un proyecto de investigación auspiciado institucional y financieramente por la Universidad de Cartagena a través de su Centro de Investigaciones Científicas y Tecnológicas, lo cual agradecemos. Ponencia leída en el IV Seminario de Historia del Caribe Colombiano, realizado en Cartagena entre el 29 de mayo y el $1^{\circ}$ de junio de 2001 .

2. Ver Sierra, Luis F. El tabaco en la economía colombiana del siglo XIX. Bogotá, U.N., 1971. 
nistrando una valiosa carga de bajada, necesaria para la rentabilidad de la navegación a vapor por el río Magdalena ${ }^{3}$, entre el interior andino y los puertos de la Costa Atlántica, especialmente la pujante Barranquilla. Antes de esa fecha, entre fines de los cuarenta y comienzos de los sesenta, fue la zona de Ambalema, en el alto Magdalena, la que desempeñó el papel de principal centro productor y exportador de tabaco en rama para Europa; pero a partir del año 1863 ese papel lo asume la comarca de los Montes de María, con eje en la antigua provincia de El Carmen de Bolívar; y lo mantiene hoy.

Gracias al auge tabacalero exportador, iniciado a mitad del S. XIX, El Carmen de Bolívar adquiere importancia en el ámbito de la provincia costeña: atrayendo capitales y negociantes tanto nacionales como extranjeros, aumentando su población de manera inusitada y acrecentando sus rentas públicas. Al respecto, Posada Carbó señala el hecho de que en el año 1870 "el Carmen contaba con un número mayor de contribuyentes que Barranquilla en el recién creado impuesto sobre la renta, aunque la capacidad tributaría de los barranquilleros seguía siendo más alta que la de los carmeros"4.

Gracias al protagonismo económico que logró en la región costeña y, en consecuencia, a su crecimiento demográfico, la comarca de El Carmen fue escalando posiciones en el mapa político del otrora Estado de Bolívar; así, del simple distrito parroquial que fue antes de 1851, pasando luego por cabecera de cantón y de circuito judicial, asiento de oficina de hacienda y fugazmente uno de los departamentos del Estado de Bolívar, llegó a convertirse en capital de la antigua Provincia de El Carmen, establecida por la constitución del año 1860, entidad político-administrativa que

3. Nieto Arteta, Luis Edurdo. Economía y cultura en la historia de Colombia. Bogotá, El Áncora, 1941; y Nichols, Theodoro E. Tres puertos de Colombia, Bogotá, Banco Popular, 1973.

4. Posada Carbó, Eduardo."Progreso y estancamiento", en Meisel Roca, Adolfo (editor). Historia económica y social del Caribe colombiano. Bogotá, Uninorte, 1994, p. 250; ver del mismo autor El Caribe colombiano. Una historia regional (1870-1950). Bogotá, El Áncora, 1998, p. 91. 
cobijaba los distritos de El Carmen, San Jacinto, Guamo, San Juan y Zambrano, siendo una de las once provincias en que se dividió dicho Estado. Esta condición aunque la perdió 26 años después con la constitución de 1886, cuando su distrito municipal es incorporado a la Provincia de Cartagena, la volvió a recuperar en 1895, y la mantuvo por treinta años más, hasta 1925, año en que la Asamblea Departamental suprimió el antiguo régimen de provincias.

\section{LA PRESENCIA EXTRANJERA}

Nuestro país no participó de la inmigración masiva de europeos a la América Latina, que se dio en el período entre 1870 y $1930^{5}$. Pero esto no quiere decir que el tema de la presencia extranjera en esa época no cobre ninguna importancia en relación con el desarrollo de nuestra historia económica y social. Porque si bien, no se dio inmigración masiva, sí se da, especialmente en la Costa, como región portuaria y de contactos comerciales con el exterior, cierta inmigración extranjera de tipo comercial o empresarial, cuya importancia económica y social ha sido resaltada por algunos historiadores como Posada Carbó $^{6}$, Manuel Rodríguez Becerra y Jorge Restrepo Restrepo.

Estos últimos han demostrado como "entre los factores sociales que incidieron en la rápida transformación de Barranquilla, existe uno que se destaca: la presencia de un núcleo de inmigrantes extranjeros que progresivamente se fue instalando en la ciudad, cuyos miembros se fueron ubicando en posiciones claves dentro de las actividades económicas fundamentales, como lo fueron el

5. Sánchez-Albornoz, Nicolás. "La población de América Latina”, en Bethel, Leslie (editor y compilador). Historia de América Latina. Tomo VII. Barcelona, Crítica/Cambridge, 1992, p. 113.

6. Fawcett, Louise y Posada Carbó, Eduardo. “Árabes y judíos en el desarrollo del Caribe colombiano, 1850-1950”, en Boletín Cultural y Bibliográfico. Bogotá, Banco de la República, volumen XXXV, º 49, 1998, Santafé de Bogotá (aparecido el año 2000), pp. 3 y ss. 


\section{EL TALLER DE LA HISTORIA 2}

transporte y el comercio durante la mayor parte del siglo XIX y en la conformación de la industria local",

Por otro lado, ha señalado así mismo Posada Carbó, en su libro sobre el Caribe colombiano, al examinar el caso de Barranquilla, el hecho de que, "A diferencia de países como Argentina y Brasil Colombia no atrajo grandes flujos de inmigrantes. De allí que la presencia de inmigrantes y capitales extranjeros en la costa sea digna de especial atención. Su presencia se hizo sentir también - agrega- en otras áreas de la región distintas de Barranquilla...". Es El Carmen de Bolívar y su comarca, precisamente, por el temprano desarrollo de su economía exportadora, con mercados en Europa, y dada su ubicación geográfica a menos de 7 leguas del río Magdalena, como parte del hinterland de la metrópoli portuaria de Barranquilla, una de esas áreas de la Costa donde más se hace sentir la presencia de inmigrantes y capitales extranjeros de que habla Posada Carbó, algunos incluso se establecen y prosperan originalmente en El Carmen, atraídos por el tabaco, y luego se expanden y se centran en Barranquilla y Cartagena, como lo vamos ver.

Las actas del censo de 1870 dan testimonio de esa inmigración empresarial en la comarca carmera, al registrar la presencia de 16 extranjeros en el círculo de El Carmen, de los cuales, casi todos, 14 en total, son europeos (ingleses, holandeses y alemanes). De esta última cifra 10 figuran como comerciantes; hecho significativo, puesto que se trata de una zona en donde el gran artículo de comercio, objeto de exportación, era el tabaco 9 .

7. Rodríguez Becerra, Manuel y Restrepo Restrepo, Jorge. "Los empresarios extranjeros de Barranquilla 1820-1900”, en Bell Lemus, Gustavo (compilador). El Caribe colombiano selección de textos históricos, Barranquilla, Uninorte, 1988, p. 139.

8. Posada Carbó, Eduardo. El Caribe colombiano. Una historia regional (1870-1950). Bogotá, El Áncora, 1999, p. 314. Las cursivas son nuestras.

9. Blanco Romero, Wilson. "Tabaco y comercio en El Carmen de Bolívar a media dos del siglo XIX”, en Huellas (Revista de la Universidad del Norte), $\mathrm{N}^{\circ} 54$, diciembre de 1998, pp. 43, 45 y 46. 
La revisión de los libros de protocolo antiguos de la Notaría Unica de El Carmen de Bolívar, permite ver cómo diversas casas de comercio europeas operaban en El Carmen, realizando préstamos hipotecarios o "avances" en dinero, para ser pagados en tabaco para la exportación; esto, desde años muy tempranos. Ese fue el caso de la casa de comercio de los Sres. Pouble Gosser y Cía., que en el año 1859 da por cancelada la obligación hipotecaria que había adquirido con ellos en el año 1856 el presbítero Manuel José de la Madrid al haber recibido la suma de $\$ 400.00$ moneda de ley para compra de tabaco con destino a dicha compañía ${ }^{10}$. Al iniciarse el S. XX, algo más de 20 años después de terminado el auge tabacalero exportador a nivel nacional, El Carmen de Bolívar se mantiene como emporio tabacalero para la exportación a gran escala, con la presencia de por lo menos seis casas de comercio europeas, operando en la región por sus propios dueños o por apoderados extranjeros, como son: 4 alemanas (Adolfo Held de Bremen, Flohr Priece \& Co., O’Beme \& Cía. y Wehdeking, Tocke \& Co. de Bremen) y 2 italianas (las de Gallo \& Matera y la de Antonio Matera) ${ }^{11}$.

Es importante observar que, ya entrado el siglo XX, El Carmen no sólo atraía capitales y grandes negociantes por ser un centro productor y exportador de tabaco, sino además porque aunaba a esa condición la de gran centro ganadero, como que fue la cuna del ganado cebú en Colombia ${ }^{12}$; y también productor de café, en la

10. Archivo Histórico de Cartagena protocolos notaria única de El Carmen de Bolívar (en adelante A. H. C. protocolo E. C. B.) tomo único de 1859, $\mathrm{N}^{\circ} 3$ folio 6; cfr. Viloria de la Hoz, Joaquín. "El tabaco de El Carmen. Producción y exportación de tabaco de los Montes de María (1848-1893)", en Aguaita (Revista del Observatorio del Caribe Colombiano), Cartagena de Indias, junio de 2000, $\mathrm{N}^{\circ} 3$, pp. 63-82.

11. Ver A. H. C protocolo. E. C. B. tomo único del año 1901.

12. Oeding, Guillermo. Zambrano cuna del cebú. Cartagena, s.f; y Meisel Roca, Adolfo y Viloria de la Hoz, Joaquín. "Los alemanes en el Caribe colombiano. El caso de Adolfo Held, 1880-1927”, en: Boletín Cultural y Bibliográfico del Banco de la República, $\mathrm{N}^{\circ}$ 49. 
106 EL TALLER DE LA HISTORIA 2

zona de La Cansona, con fábricas para el consumo local y ensayos de exportación a Europa ${ }^{13}$.

\section{LOS ITALIANOS DE EL CARMEN}

De la pequeña, pero muy importante corriente comercial de inmigrantes europeos que hace presencia en El Carmen de Bolívar y su comarca, hacia la primera década del siglo XX, la aportación italiana es la más directa y de mayor permanencia y profundidad. Con una vigencia que, de cierta forma, se mantiene plenamente viva hoy día.

Lo anterior no obstante que, a diferencia de los alemanes, y de los franceses que se vinculan en la coyuntura de la primera guerra mundial, los negociantes italianos fueron los que llegaron y empezaron su vida empresarial, con el más modesto perfil, pues, desde un principio, no operaron a través de fuertes sociedades comerciales ya constituidas y con un gran caudal, como lo harán después.

Pero esos inicios modestos de los inmigrantes ítalos, que se tradujeron en un papel, al comienzo, de mercaderes, joyeros, negociantes de finca raíz y prestamistas de pueblo, no fueron obstáculo para que al llegar y afincarse en la sub-región, aportando su iniciativa empresarial, tras el paso de los años se convirtieran en importantes hombres de negocios, cuya actividad empresarial, desbordó grandemente los límites geográficos de la comarca "monte- mariana". Tal es el caso de los Volpe, los Frieri, los Gallo y los Matera, especialmente.

El pionero de la inmigración empresarial italiana fue Antonio Volpe Romaniello. Este, según nos cuenta Don César Frieri, llegó a El Carmen en el transcurso de la última década del siglo XIX: "él fue quien trajo a los demás, incluido mi padre Salvador Frieri, quien llegó muy joven a El Carmen. Los Volpe eran 4 hermanos: Antonio,

13. Entrevista personal con Don César Frieri en 1997.

14. Entrevista telefónica con Don César Frieri efectuada en Cartagena IX-29-1999. 
Vicente, Emilio y otro cuyo nombre no recuerdo (debe ser Cayetano Volpe)"14; ya en el lejano año de 1900, el mencionado Antonio Volpe firma en El Carmen, como testigo, una escritura de fianza, en plena guerra de "Los Mil Días"15.

Sobre Vicente Gallo, quien no demoraría en trasladarse de El Carmen a Cartagena, sabemos que, entre los años veintes y treintas del siglo pasado, se convirtió en uno de los más importantes comerciantes de la capital del Bolívar Grande de entonces, llegando a ser directivo de la Cámara de Comercio de esta ciudad ${ }^{16}$; fue vocal desde 1932 y en 1934 fue su Tesorero al lado de personajes del empresariado cartagenero como Lácides Segovia, quien era su Presidente, y Daniel Lemaitre su Vice-presidente.

El mencionado Vicente Gallo, al parecer como los Volpe, llegó procedente de U.S.A. a El Carmen de Bolívar, a donde lo trajo su hermana Angelina Gallo y su cuñado Antonio Gallo, el esposo de la misma, quienes habían llegado primero; y antes de radicarse en Cartagena estuvo trabajando para ellos en negocios de distribución de joyas por el Sinú ${ }^{17}$. Y sobre los Matera, encontramos que: "Rafael Matera hijo de Pascual Matera de San Jacinto negociaban

15. A.H.C. protocolo E.C.B N ${ }^{\circ} 12 \mathrm{IX}-1^{\circ}-1900$.

16. Ver Gaceta Comercial de la Cámara de Comercio de Cartagena $N^{\circ} 80$ de 1-1 ${ }^{\circ} 1932$ y Revista de Comercio de la Cámara de Comercio de Cartagena N 97 de VI-30-1934.

17. Entrevista telefónica con Don César Frieri efectuada en Cartagena en IX-29-1999. En esta entrevista Don César me aclaró que este Vicente Gallo, que si bien llegó con los mencionados Gallo a El Carmen y poco después se radica en Cartagena, no es el mismo Vicente Gallo Gallo que en 1921 aparece comprando a Antonio Gallo U. su almacén de mercancías, ubicado en la plaza de "Molongo" [hoy de Santander] en El Carmen, con todos sus muebles y enseres incluida "una existencia de joyas con sus respectivas maletas; dos bestias caballares y una mular; cesión de todos los saldos deudores que declaran los libros de cuentas del otorgante"; y en 1933, así mismo, figura comprando a Angelina Gallo Vda. de Gallo, a la Srta. Velia Rosa Gallo G. y a las menores de edad Ofelia y Yolanda Filomena Gallo el derecho de usufructo a perpetuidad y la nuda propiedad sobre dos casas en el barrio "Arriba" de El Carmen. Dice Don César Frieri que este Vicente Gallo Gallo era hijo de los mencionados esposos Antonio Gallo U. y Angelina Gallo, y permaneció todo el tiempo en El Carmen, a diferencia de su tío y homónimo. Ver A.H.C. protocolo escritura 122 VIII-16-1921 y esc. 7 1-10-1933. 
108 EL TALLER DE LA HISTORIA 2

tabaco al por mayor, fueron grandes exportadores, vinieron con Volpe y Gallo. Tuvo bodegas en El Carmen, San Jacinto, Zambrano y fábrica de Mantequilla en Zambrano, San Jacinto, Los Palmitos y Barranquilla"18.

De los comerciantes italianos vinculados al comercio de El Carmen, el de más tardía aparición en la investigación documental que hemos realizado es Nicolás Castelli, quien se encuentra en 1930 como vecino de El Carmen, comprando los derechos herenciales de dos hermanos sobre un predio rural $^{19}$; y luego, lo vemos realizando embarques de decenas de toneladas de tabaco para Europa, desde el puerto de Barranquilla, entre los años 1931 y $1935^{20}$.

Italia, patria de estos empresarios, no sólo no constituyó, hasta donde sabemos, un mercado importador de tabaco en rama, como sí lo fueron, Inglaterra, Alemania y posteriormente Francia, sino que tampoco llegó a constituir parte del centro capitalista europeo. Pero, no obstante esas circunstancias, llama la atención el hecho de que, dentro de la pequeña corriente de inmigrantes extranjeros que se establecieron en El Carmen, fueron los inmigrantes italianos los más numerosos, los de mayor permanencia y continuidad, y así mismo los de mayor raigambre social y económica en la comarca "montemariana" y el propio Carmen de Bolívar.

$\mathrm{Al}$ respecto de lo anterior, registramos hechos que nos permiten constatar cómo esas familias de empresarios italianos se integraron a lo que se podría llamar la élite de la comarca carmera, jugando un papel prominente no sólo en la vida económica, sino también en lo social y cultural. Así, en lo que hace a las tradiciones festivas y populares, ya para el año de 1920 aparece una elocuente nota en el periódico carmero "Ecos de la Montaña", del siguiente tenor: "LOS SRS. VOLPE Y EL SR. FRIERY (sic.) acaban de com-

18. Entrevista telefónica con Don César Frieri Id. supra.

19. A.H.C. protocolo $\mathrm{N}^{\circ} 37 \mathrm{~V}-9-1930$.

20. A.H.C. Gaceta Departamental 1931 № 6129 111-31-1931; 1932 Nº 6395 111-5- 1932; $1933 \mathrm{~N}^{\circ} 7064$ VII-4-1934; $1934 \mathrm{~N}^{\circ} 7083$ VIII-1 ${ }^{\circ}-1934,7093$ VIII-16- 1934, 7097 VIII-21-1934 y 1935 Nº 7410 IX-20-1935. 
prar 50 toros valientes para la fiesta del 11 de Noviembre" ${ }^{21}$. Y años después en 1933 encontramos otro hecho significativo en relación con lo dicho arriba: vemos a Don Salvador Frieri asumiendo el cargo de "Tesorero de la Junta de Damnificados de El Carmen creada por el art. 2- de la Ley 21 de 1933 con motivo de los estragos causados por la inundación del arroyo Alférez, el cual atraviesa la localidad, que ocasionó la destrucción de las casas de 35 hogares...."22. Pero para los fines propios de este artículo, dejemos este aspecto hasta allí y pasemos a ocupamos enseguida del caso de los Volpe en particular.

\section{EL CASO DE LOS VOLPE}

Hagamos ahora un breve recorrido, que nos acerque a lo que fue la evolución histórica de estos empresarios e inmigrantes italianos en la comarca carmera y aún más allá de ella, a partir de comienzos del recién fenecido siglo XX.

De las tantas compañías o casas de comercio extranjeras vinculadas a la exportación del tabaco de El Carmen, fue la de Antonio Volpe \& Cía. la de mayor desarrollo, permanencia continua en la comarca y expansión fuera de ella. Esta firma, además de la exportación e internación de tabaco, tuvo como su otro renglón de inversión la tenencia de ganado en grande; además de la venta de mercancías en general y de joyas de oro.

La sociedad comercial Antonio Volpe \& Cía. se constituyó en El Carmen de Bolívar en el año 1907 con un capital de $\$ 9.000$ oro americano, aportados por sus tres socios; todos inmigrantes italianos (Antonio Volpe, Nicolás Romaniello y Salvador Frieri), los dos primeros de Padua o "Padula", como aparece en los documentos, y el último de Cairamo. Se constituyó dicha Cía. con domicilio en El Carmen, y con el objetivo de "especular en las negocia

21. A.H.C. “Ecos” No 139 VIII-21-1920.

22. A.H.C. protocolo E.C.B. N 52 V-2-1934. 


\section{EL TALLER DE LA HISTORIA 2}

ciones de mercancías, tabaco, prendas, ganados...". El socio con la mayor porción del capital social era Antonio Volpe, quien aportó casi el $70 \%$ del mismo ${ }^{23}$.

En 1912, al parecer, se retira Salvador Frieri, quien continuará independientemente sus negocios de almacén de variadas mercancías, ganadería, especulación con finca raíz y préstamos hipoteca$\operatorname{rios}^{24}$; llegando a ser considerado, por mucho tiempo, como "el banco" de El Carmen, "...eje sustantivo de los negocios de esta región" como se refería a él un comentario de la redacción del periódico Ecos de la Montaña en $1929^{25}$.

En ese mismo año de 1912 Antonio Volpe y Cía. constituye asociación de comercio con dos inmigrantes italianos más, los Sres. Pascual y Miguel Matera del comercio de San Jacinto. Y en el temprano año de 1913, con la vinculación a la sociedad comercial de Vicente Volpe, un hermano de Antonio, la firma se expande a Barranquilla, estableciendo así otro domicilio, además del original en El Carmen; y abre, además, sucursal en San Jacinto $^{26}$. Un aviso de la prensa local anuncia el almacén de mercancías de la compañía, establecido en lugar central de El Carmen: "Antonio Volpe y $\mathrm{C}^{\mathrm{a}}$. Permanente surtido de mercancías a precio sin competencia" 27 , reza el aviso. A partir de entonces, el nombrado Vicente Volpe empieza a figurar como apoderado general de la compañía en las actas notariales que registran negocios de la misma ${ }^{28}$.

Otro anuncio de la prensa, de 1914, ofrece un claro testimonio de la expansión comercial de esta nueva sociedad Antonio Volpe \& Cía. a la cual entró a formar parte Vicente Volpe [coincidiendo, al parecer, con la salida de Salvador Frieri]. Entonces diversifican

23. A.H.C. protocolo E.C.B. $\mathrm{N}^{\circ} 63$ IV-4-1907.

24. Ver A.H.C. protocolo E.C.B. $\mathrm{N}^{\circ} 135$ VI-24-1913.

25. A.H.C. "Ecos" N 341 VI-19-1929.

26. A.H.C. Id. $\mathrm{N}^{\circ} 110 \mathrm{~V}-17-1913$.

27. A.H.C. “Ecos” E.C.B. No 12 1-18-1914.

28. Ver por ejemplo A.H.C. protocolo E.C.B. № 3 1-8-1913. 
aún más sus negocios y amplían la venta de mercancías, llamando la atención el hecho de que se anuncian como importadores de diversas mercaderías incluyendo "joyas de oro y piedras preciosas" y como exportadores no solo de tabaco sino también de "oro en polvo,...bálsamo y pieles"29.

En 1915, los Volpe prorrogan por dos años la asociación de comercio que habían constituido con lo Sres. Pascual y Miguel Matera $^{30}$; y seis años después ya los vemos establecidos en Barranquilla $^{31}$. Así, encontramos en la revisión documental al Sr. Vicente Volpe figurando en 1921 como socio administrador de la casa comercial que "gira en Barranquilla" como "Antonio Volpe i Cía." 32 , lo cual, desde luego, marca un hito en el proceso de expansión y fortalecimiento empresarial de estos italianos. En este mismo año queda constituida la "Compañía Regular Colectiva de Comercio Volpe i Matera en virtud del contrato firmado entre Vicente Volpe como socio administrador de la casa comercial que gira en Barranquilla como "Antonio Volpe i Cía." y Pascual y Miguel Matera, del comercio de San Jacinto" ${ }^{33}$.

A finales de 1925 — partícipe de la modernización de los medios de comunicación - la firma Volpe \& Matera a través de su apoderado Miguel Matera:

"otorga poder al Sr. Leopoldo Lascarro B, domiciliado en Bogotá, para que proceda a solicitar de la división general de correos de la República permiso para establecer una línea telefónica entre la población de Zambrano y su hacienda nombrada "Puerto Nuevo",

29. A.H.C. protocolo E.C.B. $N^{\circ} 12$ 1-18-1914.

30. A.H.C. Id. $\mathrm{N}^{\circ} 52 \mathrm{~V}-2-1915$.

31. En 1916 Cayetano Volpe era el socio principal (con el $45 \%$ del capital) de la fábrica de vidrios La Veneciana". Cfr. Solano de las Aguas, Sergio Paolo. "Acumulación de capital e industrias. Limitaciones en el desarrollo fabril de Barranquilla, 1900-1934" en Historia y Cultura, revista de la Facultad de Ciencias Humanas de la Universidad de Cartagena, $\mathrm{N}^{\circ} 2$, p. 222; agradezco al autor el haberme aportado esta nota.

32. A.H.C. Id. N 66 V-20-1921.

33. A.H.C. Id. $\mathrm{N}^{\circ} 66 \mathrm{~V}-20-1921$. 


\section{EL TALLER DE LA HISTORIA 2}

situada sobre la margen izquierda del Río Magdalena jurisdicción del Distrito del mencionado Zambrano, puntos entre los cuales media una distancia de diez (10) kilómetros aproximadamente,... ${ }^{34}$

Para este mismo año: por un lado, Antonio y Vicente Volpe, como únicos socios de $\mathrm{A}$. Volpe y Cía. domiciliada en Barranquilla $^{35}$ declaran disuelta su antigua sociedad y por medio de otra escritura constituyen una nueva sociedad, A. Volpe y Cía., domiciliada en Barranquilla; y por el otro lado, Pascual y Miguel Matera en su calidad de únicos socios de P. \& M. Matera, socio colectivo de A. Volpe y Cía. de Barranquilla, habiéndose disuelto la antigua sociedad con ese nombre, aceptan como socio colectivo a la nueva sociedad constituida con el mismo nombre y cuyos único socios son Antonio y Vicente Volpe ${ }^{36}$.

En 1926 se prorroga por dos años la escritura de constitución de la sociedad comercial Volpe \& Matera: "La prórroga se hace por el término de 2 años, bajo las mismas condiciones expresadas en la escritura constitutiva, pero con algunas modificaciones que aquí se expresan : 1) Retirar del capital social \$200.000.00 oro americano por parte del socio Antonio Volpe \& Cía. retiro que se efectuará dentro del curso de 2 años desde el día que empiece a regir la prórroga...2) Se admite como socio a Miguel Alliegro [otro inmigrante italiano] de este vecindario [El Carmen] quien aporta a

la sociedad $\$ 8.000 .00$ oro americano en efectivo... ${ }^{37}$ Dicha sociedad, Volpe \& Matera, se disuelve en 1928 mediante acto notarial efectuado en la Notaría Unica de El Carmen de Bolívar ${ }^{38}$.

De acuerdo con lo anterior es importante resaltar como la magnitud de la suma de $\$ 200.000 .00$ oro americano, en ese entonces retirada del capital social por los Sres. Antonio Volpe \& Cía.,

34. A.H.C. Id. $\mathrm{N}^{\circ} 201$ XI-5-1925.

35. Como se ve ya aquí ha quedado Antonio Romaniello por fuera de la sociedad.

36. A.H.C. protocolo $\mathrm{N}^{\circ} 237$ XII-19-1925.

37. A.H.C. protocolo $\mathrm{N}^{\circ} 101 \mathrm{~V}-15-1926$.

38. A.H.C. protocolo $\mathrm{N}^{\circ} 57 \mathrm{~V}-15-1928$. 
es un evidente indicativo de la gran acumulación de capital lograda por dicha firma tras sólo 19 años de operaciones, puesto que esa suma equivale a multiplicar por 22 veces el capital social de $\$ 9.000 .00$ oro americano con el que se había constituido dicha Cía. en El Carmen en el año de 1907. Lo que hace pensar asimismo en lo significativo del incremento, variedad y expansión de las operaciones comerciales de estos empresarios italianos, y atestigua su rápido éxito económico.

La expansión de la empresa continuó no obstante la sangría de capital, tal como lo demuestra el hecho de que en 1928 la sociedad comercial Antonio Volpe \& Cía. por medio de su socio administrador Vicente Volpe:

"otorga poder general al Sr. Miguel Alliegro para administrar los negocios de que se ocupa la casa comercial Antonio Volpe \& Cía. de esta ciudad [El Carmen] y de la sucursal establecida en Zambrano: compra y venta de mercancías, de ganado y de frutas, compra y venta de inmuebles, girar y endosar letras de cambio,..."39

En el año 1932 encontramos que la firma Antonio Volpe \& Cía. se mantiene en El Carmen, ya no sólo dedicada al negocio de la exportación tabacalera y la ganadería, sino que también se dedica al cultivo del tabaco; como lo muestra un aviso de una revista de la Cámara de Comercio de Barranquilla ${ }^{40}$. A propósito de su presencia en esta metrópoli portuaria de la Costa encontramos que los Volpe, que como vimos arriba aparecen ya en 1921 establecidos en esta ciudad, hacia fines de los años veintes aparecen ya ostentando una señalada preeminencia, no sólo en el gran comercio barranquillero sino que se destacan además dentro de la dirigencia del gremio empresarial de la ciudad. En una reseña histórica del año 1928 que describe la vida comercial de Barranquilla, encontramos que su autor destaca el edificio Volpe, situado en la tradicional y popular Plaza de San Nicolás, como uno de los más

39. A.H.C. Id. $\mathrm{N}^{\circ} 60 \mathrm{~V}-19-1928$. Las cursivas son nuestras.

40. Revista de la Cámara de Comercio de Barranquilla Nos. 3 a 5 VII-15-1932. 


\section{EL TALLER DE LA HISTORIA 2}

importantes de la ciudad ${ }^{41}$. Y por lo que muestra un aviso del año 1932 no queda duda de que estamos ante una gran empresa; que se movía tanto con la venta de mercancías al detai y al por mayor como con grandes negocios dentro del perfil propio de la diversificación comercial e industrial de la época; no sólo en el plano del comercio y la producción internas sino también del comercio exterior, el cual mantienen y ensanchan tras sus inicios como exportadores del tabaco de los Montes de María años atrás. Transcribamos dicho aviso:

"ANTONIO VOLPE \& CO., Barranquilla (Rep. de Col.). IMPORTACIÓN-EXPORTACIÓN-COMISIONES

Por telégrafo "Volper"

Surtido completo de mercancías, joyería fina y piedras preciosas

Ventas por Mayor

Compras de tabaco, cueros, café, tagua, bálsamo, etc., para la exportación.

Negocios de ganado y producción de tabaco, atendidos por nuestra casa del Carmen (B.)",42

Observamos, para esta misma época, la preeminencia lograda por el propio Vicente Volpe entre el gremio empresarial de Barran- quilla; es así como lo vemos figurando en la lista de miembros principales de la Cámara de Comercio de Barranquilla, al lado de: "Federico Blanco-Diofante de la Peña-Luis del ValleStanley Foster-Eduardo L. Gerlein-Edward Hughes-A.L RoncalloJ.M. Santo Domingo".

Además, de las seis comisiones permanentes de la misma Cámara de Comercio creadas para el estudio de los negocios que cur-

41. "Los almacenes de italianos y de sirios, en su mayor parte, realizan grandes ganancias. Vemos negocios de todas sus variedades de género, ferreterías, provisiones, ...con edificios como el de Mogollón, el de Palma, el de Correa y Blanco, el Pacini Pucini, el de Volpe y otros vistosos y capaces...” ver Abello N., Jorge. Barranquilla, 1877-1927. El Panorama de Medio Siglo (Folleto). Barranquilla, Departamento de Historia de la Universidad del Atlántico, 1994, p. 7. El resaltado es nuestro. 
sen, él también forma parte de dos de esas comisiones: la de Agricultura y la de Aduana ${ }^{43}$. Dos años después, en 1934, figura ya como Primer Vice-Presidente de la Junta Directiva de dicha Cámara de Comercio al lado de Julio Mario Santo Domingo, Presidente, y Ramón Emiliani Vélez, Segundo Vice-Presidente. ${ }^{44}$ De otra parte constatamos que la firma Antonio Volpe y Cía. de Barranquilla mantiene su casa de comercio en El Carmen de Bolívar con negocios de ganado y producción de tabaco allí para exportación ${ }^{45}$.

Por otra parte, aunque carecemos de estadísticas completas, la información cuantitativa complementada con la cualitativa, nos lleva a establecer que, la exportación de tabaco de la comarca carmera constituyó una actividad principal en la amplia gama de diversos negocios desarrollados por la firma Volpe, en sus 6 décadas de vinculación permanente a dicha comarca.

Al propio Antonio Volpe, desde 1905, pocos años después de establecido en El Carmen y vinculado a su comercio, poco antes de constituir su compañía, lo vemos invirtiendo sumas importantes en diversos negocios de "avance" con pago en tabaco de exportación ${ }^{46}$.

En cuanto a la sociedad Antonio Volpe \& Cía. se refiere, sabemos que entre los objetivos estipulados en la escritura de constitución se establece el de "especular en negociaciones de... tabaco ${ }^{47 "}$ ". Efectivamente para el año 1910 ya encontramos testimonios de la prensa oficial de la época, que constatan la temprana participación de esta sociedad en el negocio de la exportación tabacalera; se relacionan guías de exportación y de internación, expedidas en la colecturía de Hacienda del Distrito de San Jacinto correspondiente al mes de enero de dicho año, que dan cuenta de la exportación de

43. Ver Id. supra.

44. Revista de la Cámara de Comercio de Barranquilla Nos. 27 a 30 VI-30-1934.

45. Revista de Comercio de la Cámara de Comercio de Cartagena Nº 97 VI-30-1934.

46. Ver A.H.C. protocolo. $N^{\circ} 84$ IV-5-1905. 


\section{EL TALLER DE LA HISTORIA 2}

160 bultos (10.4 toneladas) y la internación de 37 bultos de tabaco de cuenta de A. Volpe y Cía ${ }^{48}$.

En la escritura de modificación de los estatutos de la Cía. que da lugar en 1913 a la vinculación de Vicente Volpe y al establecimiento de otro domicilio comercial en Barranquilla, vemos que la exportación tabacalera en la comarca carmera sigue contando entre los objetivos de esta sociedad ${ }^{49}$.

Ahora, revisando cifras, encontramos que, durante los años de 1918, 1919 y 1920 A. Volpe y Cía. exportaron un total de 21.119 bultos de "Tabaco del Carmen de Bolívar" (equivalentes aprox. a 1.328 toneladas de la hoja) generando un ingreso de divisas por $\$ 404.389 .00$ oro americano. ${ }^{50}$ Datos que dan prueba palpable de la gran magnitud que alcanzaron los negocios de exportación tabacalera desarrollados por esta firma en la comarca carmera.

En 1921, al asociarse con la firma P. y M. Matera de San Jacinto, constituyendo la "Compañía Regular Colectiva de Comercio", identificada con la razón social de "Volpe i Matera", continúan desde allí con la exportación tabacalera como lo ilustra de manera directa un aviso que reza: "Volpe \& Matera: exportación de tabaco, de pieles, fuertes tenedores de ganado" 51 .

En 1932 la firma en cuestión, tras la disolución en 1928 de su asociación de comercio con P. y M. Matera, después de 14 años de matrimonio mercantil ${ }^{52}$, continúa por su propia cuenta con el negocio del tabaco de El Carmen, como podemos ver en aviso publicitario que citamos más arriba ${ }^{53}$. Lo que se repite en otro aviso similar del año 1934 que indica: “...Antonio Volpe y Cía. De Barran-

47. A.H.C. Id. $\mathrm{N}^{\circ} 63$ 1V-4-1907.

48. A.H.C. Id. $\mathrm{N}^{\circ} 95$ V11-16-1910.

49. Ver A.H.C. protocolo $\mathrm{N}^{\circ} 110 \mathrm{~V}-17-1913$.

50. A.H.C. "Ecos” E.C.B. N 64111-23-1922. Editorial "Don Francisco Degioanni G."

51. A.H.C. Id. $\mathrm{N}^{\circ} 147$ Vl-4-1921. Las cursivas son nuestras.

52. A.H.C. protocolo $\mathrm{N}^{\circ} 57 \mathrm{~V}-15-1928$.

53. Revista de la Cámara de Comercio de Barranquilla Nos. 3 a 5 Vll-15-1932. 
quilla. Con casa de comercio en El Carmen de Bolívar con negocios de ganado y producción de tabaco allí para exportación..."54

Para 1935 constatamos que dicha compañía efectuó la internación de 263 bultos de tabaco en rama, con peso de 16.3 toneladas netas, a los municipios de Bogotá, Girardot y Ciénaga; y 44 bultos de tabaco en rama con peso neto de 2.8 toneladas, con destino al exterior por la vía de Barranquilla ${ }^{55}$.

Y, aún diez años después, en 1946 entre "las principales firmas que negocian en tabaco de El Carmen y que se hallan radicados en la ciudad o mantienen agencias especiales..." encontramos a Antonio Volpe \& Cía. al lado de otros exportadores italianos o de origen o ascendencia italiana como son P. \& M. Matera, Antonio Gallo y César Frieri (este último hijo, recientemente fallecido, del inmigrante italiano Salvador Frieri) ${ }^{56}$.

Digamos, finalmente, que el mismo César Frieri que acabamos de mencionar, nos dio un vivido testimonio de cómo la continua y prolongada presencia de la mencionada compañía de los Volpe en el negocio de la exportación de tabaco de El Carmen en gran escala, se prolongó más allá de la primera mitad del S. XX; cuando, en una de las tantas entrevistas sostenidas sobre esta historia de la cual él fue protagonista, nos refirió lo siguiente: “...como en el año 1958 me coloqué [en El Carmen] como representante comisionista de A. Volpe \& Cía. al frente de una factoría de tabaco... Tuve una factoría de tabaco con 120 obreros, el tabaco se fermentaba, se clasificaba y más tarde se empacaba y se mandaba a las bodegas de Barranquilla de la firma Antonio Volpe \& Cía ${ }^{57}$

Como colofón, agreguemos que las familias de comerciantes italianos que llegaron y se establecieron en El Carmen, entre el

54. Revista de Comercio de la Cámara de Comercio de Cartagena N ${ }^{\circ} 97$ Vl-30-1934.

55. A.H.C. Gaceta Departamental Nº 7361 Vll-19-1935.

56. Contraloría de Bolívar, El Carmen B. Publicaciones de la Contraloría de Bolívar, 1946, y entrevista con el señor Hans Kulman en Cartagena X-29-1998.

57. Entrevista con Don César Frieri en Cartagena XII-20-1997. 


\section{EL TALLER DE LA HISTORIA 2}

ocaso del siglo XIX y el orto del XX, atraídos fundamentalmente por su tabaco, además de su contribución al desarrollo económico han aportado, una cuota de consanguinidad en la formación y el desarrollo moderno del pueblo carmero, que perdura en nuestros días. Basta ojear las páginas del directorio telefónico del actual Carmen de Bolívar, para encontrar entre los abonados varias decenas de sus descendientes cabezas de hogar. Allí están los Frieri, los Gallo, los Mazzeo e incluso los Castelli, que ahora figuran con una sola "L"; como prueba viviente, de la historia imperecedera del aporte que unos hijos de la bota itálica, le dieron al que es hoy el pueblo de sus hijos, nietos y bisnietos, 100 años atrás ${ }^{58}$.

58. En Cartagena encontramos un nieto de Antonio Volpe Romaniello, el señor Alvaro Volpe Fernández, nacido en El Carmen de Bolívar en el año 1950 hijo de Carlos Volpe (q.e.p.d.), este último nacido en El Carmen de Bolívar y a su vez hijo del nombrado Antonio Volpe Romaniello, el hermano mayor del famoso empresario Don Vicente Volpe y fundador homónimo de la firma Antonio Volpe y Cía. de El Carmen, posteriormente establecida en Barranquilla, de la cual tanto nos hemos ocupado acá. Entrevistas telefónicas, efectuadas en Cartagena; en X-18-2000 con la mujer del mencionado señor. Alvaro Volpe Fernández y posteriormente en XII-2-2000 con el mismo señor Alvaro. 